\title{
Experimental Study on The Performance of Fiber Reinforced RAC
}

\author{
Mingming Zhang ${ }^{a}$, Shimin Zhang ${ }^{b^{*}}$, Xiaohui Peng ${ }^{c}$ and Kangning Liu ${ }^{d}$ \\ School of Civil Engineering, Xijing University, Xi'an 710123, China \\ a649296570@qq.com, bzhangshimin@aliyun.com, ${ }^{5} 565938711 @ q q . c o m,{ }^{d} 1971576166 @ q q . c o m$
}

Keywords: Regenerated fibre; Intensity ratio; Deformation property; Mechanical properties

\begin{abstract}
In order to study the fiber of fiber recycled concrete (F-RAC) on the mechanical properties and deformation performance, through the 72 groups of 216 pieces of concrete specimens of different substitution rate of RAC were studied, the results showed that the addition of a single fiber, the flexural strength of RAC were higher than that of the reference concrete, and increased significantly, the largest increase of substitution rate was 50\% with RSF-1 regeneration of radial steel wire fiber, increased by $27.8 \%$, the smallest increase has reached about $11 \%$; the peak strain decreased with the added fiber, elastic modulus in the replacement rate is $30 \%$ and $50 \%$ of the RAC doped fiber, in addition to add RAC RSF-1, elastic modulus were decreased by $5.8 \%$ and $2.5 \%$, the rest of the fiber elastic modulus of RAC were improved; on the replacement rate is $30 \%$ and $50 \%$ PPF-1, and in PPF-2 doped and RSF-1 and not adding fiber RAC, tangential slope of basic phase When the stress increases, the tangential elastic modulus of RAC without adding fiber is relatively large, and the tangential elastic modulus of concrete is decreased after the addition of fiber.
\end{abstract}

\section{Introduction}

Fiber reinforced concrete is a kind of concrete with a certain proportion of fiber in the concrete matrix, which can improve the crack resistance of the matrix and improve the toughness and bending performance. According to the mechanical properties of the fiber, it can be divided into high elastic modulus fiber concrete and low elastic modulus fiber concrete. Among them, the steel fiber concrete and polypropylene fiber concrete are the most commonly used fiber in the high and low elastic modulus fiber. For fiber recycled concrete, many scholars make a large number of experimental studies in different shapes and different types of fiber preparation of recycled concrete, such as Wu Bao [1] study on the experimental of reinforced polyethylene fiber under the performance of recycled concrete. Du Yuanfang [2] Study on the influence of recycled concrete under the mixed regenerated fiber. Li Chuanchuan [3] study on splitting strength of concrete was studied by the influence of steel fiber . Chen Aijiu [4] study the influence of basalt fiber on the mechanical properties of recycled rubber concrete . Niu Jiangang [5] study on the mechanical properties and optimum fiber content of plastic fiber reinforced lightweight aggregate concrete . Jiang Jian [6] study on the compressive properties of recycled concrete under different modification . Zhou Jinghai [7] study on splitting tensile strength of recycled fiber waste concrete .

Based on the existing research results, the mechanical properties and deformation behavior of RAC fiber reinforced concrete made of single fiber were studied by 72 sets of 216 specimens under different substitution rates.

\section{Test overview}

On the basis of "test method of mechanical properties on ordinary concrete standards"and test method of steel fiber reinforced concrete, respectively in 72 groups of 216 specimens of cube compressive strength, axial compressive strength, splitting tensile strength test, flexural strength, deformation performance. Cube and anti fracture block were used $100 \mathrm{~mm} \times 100 \mathrm{~mm} \times 100 \mathrm{~mm}$, $100 \mathrm{~mm} \times 100 \mathrm{~mm} \times 300 \mathrm{~mm}$ and $100 \mathrm{~mm} \times 100 \mathrm{~mm} \times 400 \mathrm{~mm}$ non-standard test block.

Test Materials. Fibre: the test fiber fibers were mainly two kinds of polypropylene fiber (PPF) and two recycled fiber(RF), the One is the three polypropylene mesh fibers, denoted as PPF-1; The second is modified polypropylene (coarse) TANK fiber, denoted as PPF-2. The two kinds of 
regenerated fibers are separated from the waste tires, one of which is stripped of the radial steel wire (SF), denoted as RSF-1, the second is the separation of nylon fiber (NF), denoted as RNF-2. The properties of polypropylene fiber materials are shown in Table 1and table 2.

Table 1 properties of polypropylene fiber with three branches

\begin{tabular}{cccccc}
\hline proportion $/(\mathrm{kg} / \mathrm{cm} 3)$ & 1.18 & length/(mm) & 19 & Equivalent diameter/ $(\mu \mathrm{m})$ & 49.17 \\
\hline $\begin{array}{c}\text { tensile } \\
\text { strength } /(\mathrm{MPa})\end{array}$ & 472.3 & elongation at break $/(\%)$ & 23.2 & Elastic modulus/(MPa) & 4804.6 \\
\begin{tabular}{c} 
melting point $/\left({ }^{\circ} \mathrm{C}\right)$ \\
\hline
\end{tabular} & 167 & Alkali retention rate $/(\%)$ & 99.4 & $\begin{array}{c}\text { Keep the rate of light } \\
\text { intensity } /(\%)\end{array}$ & 96.9 \\
\hline
\end{tabular}

Table 2 properties of modified polypropylene (crude) TANK fiber

\begin{tabular}{cccccc}
\hline proportion $/(\mathrm{kg} / \mathrm{cm} 3)$ & 0.91 & length $/(\mathrm{mm})$ & 50 & Equivalent diameter/ $(\mu \mathrm{m})$ & $0.9-1.1$ \\
\hline $\begin{array}{c}\text { tensile } \\
\text { strength } /(\mathrm{MPa})\end{array}$ & $>350$ & elongation at break $/(\%)$ & $10-30$ & Elastic modulus/(MPa) & $>4000$ \\
$\begin{array}{c}\text { melting point } /\left({ }^{\circ} \mathrm{C}\right) \\
\text { Keep the rate of light } \\
\text { intensity } / \%)\end{array}$ & Alkali retention rate $/(\%)$ & $\geqq 94.4$ & $\geqq 50$ \\
\hline
\end{tabular}

Mix Design. In order to study the effects of different kinds of fibers on the properties of RAC, the three kinds of fibers, PPF-1, PPF-2 and RSF-1, were added to study the changes of RAC strength and deformation under different fibers. Fiber RAC fits as shown in table 3.

Table 3 different HFC and HF-RAC ratio [ $\mathrm{kg} / \mathrm{m} 3]$

\begin{tabular}{cccccccc}
\hline $\begin{array}{c}\text { Concrete } \\
\text { types }\end{array}$ & $\begin{array}{c}\text { Fiber } \\
\text { type }\end{array}$ & Cement & $\begin{array}{c}\text { Natural } \\
\text { sand }\end{array}$ & $\begin{array}{c}\text { Natural detritus } \\
(0 \sim 20[\mathrm{~mm}])\end{array}$ & $\begin{array}{c}\text { Recycled } \\
\text { aggregate (RA) }\end{array}$ & Water & $\begin{array}{c}\text { Fiber } \\
\text { content }\end{array}$ \\
\hline \multirow{3}{*}{ HFC } & PPF-1 & 500 & 465 & 1199 & 0 & 215 & 0.9 \\
& PPF-2 & 500 & 465 & 1199 & 0 & 215 & 0.9 \\
& RSF-1 & 500 & 465 & 1199 & 0 & 215 & 0.9 \\
\hline \multirow{3}{*}{ HF-RAC-30\% } & PPF-1 & 500 & 465 & 839 & 360 & 215 & 0.9 \\
& PPF-2 & 500 & 465 & 839 & 360 & 215 & 0.9 \\
& RSF-1 & 500 & 465 & 839 & 360 & 215 & 0.9 \\
HF-RAC-50\% & PPF-1 & 500 & 465 & 600 & 600 & 215 & 0.9 \\
& PPF-2 & 500 & 465 & 600 & 600 & 215 & 0.9 \\
\hline
\end{tabular}

\section{RAC mechanical Properties Test}

Fiber RAC Strength Analysis. For single fiber F-RAC, the compressive strength, splitting tensile strength and flexural strength of concrete specimens were studied by adding PPF-1, PPF-2 and RSF-1, respectively. PPF-1, PPF-2, RSF-1 at different replacement rates were $30 \%$ and $50 \%$, in addition to the fiber corresponding to the RAC as the benchmark, the intensity of the normalization, the test results shown in figure 1.As can be seen from figure 1, the replacement rate was $30 \%$ and $50 \%$ RAC, PPF-1, PPF-2, RSF-1 three kinds of fiber reinforced effect has obvious anti bending strength of the cube compressive strength before and after adding fiber to RAC has no significant influence on the change of growth or decline were less than 5\%; for splitting tensile strength RAC-F, the relative intensity is larger, but the replacement rate is $30 \%$ when adding RSF-1 radial steel fiber has been increased smaller, while 50\% added PPF-1 has increased to a certain extent; the prism compressive strength, in addition to $30 \%$ substitution rate add PPF-2 fiber strength decreased while remaining different substitution rate have increased in varying degrees to add fiber. The results show that the strength loss rate is nearly $28 \%$, and the minimum increase is about $11 \%$, which is shown in table 4 . It can be seen that the toughening effect of fiber on concrete is better. 


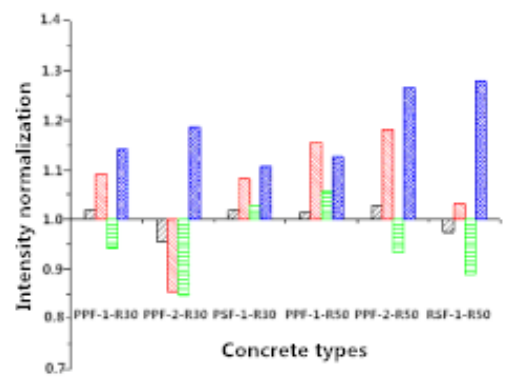

Figure 1. RAC-F intensity normalization

Table 4 RAC-F strength amplitude difference (\%)

\begin{tabular}{cccccc}
\hline $\begin{array}{c}\text { Substitution } \\
\text { rate }\end{array}$ & Fiber type & $\begin{array}{c}\text { Cube compressive } \\
\text { strength }\end{array}$ & $\begin{array}{c}\text { Prismatic } \\
\text { compressive strength }\end{array}$ & $\begin{array}{c}\text { Splitting tensile } \\
\text { strength }\end{array}$ & $\begin{array}{c}\text { Bending } \\
\text { strength ratio }\end{array}$ \\
\hline & PPF-1 & 1.84 & 9.17 & -5.77 & 14.2 \\
$30 \%$ & PPF-2 & -4.37 & -14.5 & -15.3 & 18.6 \\
& RSF-1 & 1.92 & 8.2 & 2.7 & 10.7 \\
& PPF-1 & 1.35 & 15.6 & 5.48 & 12.6 \\
$50 \%$ & PPF-2 & 2.74 & 18.0 & -6.61 & 26.6 \\
& RSF-1 & -2.56 & 3.27 & -11.0 & 27.8 \\
\hline
\end{tabular}

Analysis of Deformation Behavior of Fiber RAC. Xiao Jianzhuang [8] also shows that due to the low elastic modulus of recycled coarse aggregate RA, the elastic modulus of RAC is low and the deformation is relatively large. According to the "standard" [9] method to replace rate of $30 \%$ and 50\% RAC were mixed with three kinds of fibers (PPF-1, PPF-2 and RSF-1), the deformation properties of fiber recycled concrete based on the elastic modulus, peak strain and stress-strain curve was studied. The was used as the reference concrete with the replacement rate of $30 \%$ and $50 \%$, respectively, of the fiber RAC, and the strength of the fiber was compared before and after deformation, as shown in figure (a) (c).From Figure 2 (a) shows that when adding PPF-1, RSF-1, RAC 30\% replacement ratio (RAC30) of the peak stress does not exceed fiber RAC30 9.2\% and $8.2 \%$, but the peak value of RAC with PPF-2 fiber stress was reduced by $14.5 \%$; while the replacement ratio is $50 \% \mathrm{RAC}$ with three PPF-1, PPF-2, RSF-1 fiber the peak stress was more than mixed with fiber RAC50 15.6\%, 18\% and 3.3\%. From Figure 2 (b) shows that when adding PPF-1, NC slightly reduced $3.3 \%$ and $30 \%$ corresponding, and $50 \%$ corresponding to the RAC increased by $20.2 \%$ and $15.8 \%$; and for PPF-2 fiber, NC, RAC50 increased by $8.1 \%$ and $15.5 \%$, and RAC30 decreased $5.8 \%$; for RSF-1 regeneration of radial steel fiber, and fiber modified poly the crude propylene TANK instead, NC and RAC50 decreased by $1.01 \%$ and $2.52 \%$, while the RAC30 increased by $5.8 \%$. From Fig. 2 (c) shows that the three kinds of fiber recycled concrete in the replacement rate of $0 \%, 30 \%$ and $50 \%$ of the peak strain were lower than that of $\mathrm{NC}$ and RAC of corresponding concrete mixed with fiber, which is the largest decline in PPF-2RAC50 32.6\%, the smallest decline for PPF-2C 7.91\%.

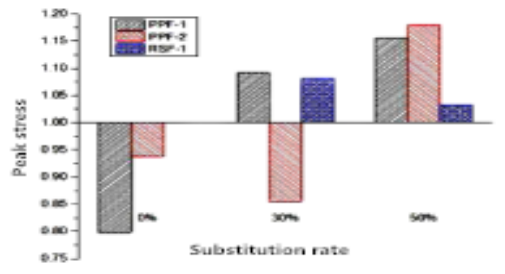

(a) $f_{\mathrm{c}}$

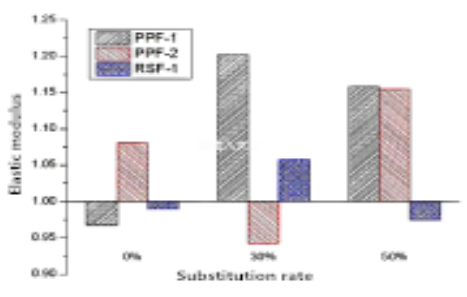

(b) $\mathrm{E}_{\mathrm{c}}$

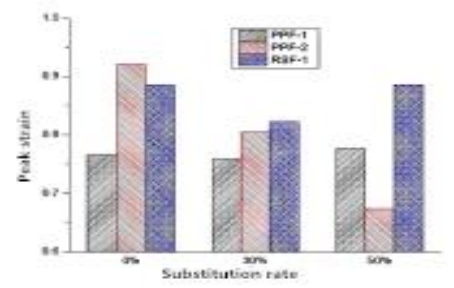

(c) $\varepsilon_{0}$

Figure 2. normalized deformation

The Relationship between Stress and Strain Modulus and Stress of Fiber RAC. The RAC stress-strain curve (rise) of the single doped fiber with the substitution rate of $30 \%$ and $50 \%$ is shown in figure (a) (b). As can be seen from Figure 3 (a), (b), it compared to NC, RAC (30\%) in 
the range, and in 50\% with PPF-1, PPF-2 and RSF-1 and not adding fiber RAC, tangential slope is basically the same, but the stress continues to increase, not adding fiber RAC30 and RAC50 and the tangential elastic modulus is large, while adding fiber concrete was reduced. For the RAC with the substitution rate of $30 \%$, the strain of RAC30 concrete under the same stress is larger than that of PPF-1, which is more than PPF-2 and RSF-1, and the tangential modulus is the lowest, RSF-1RAC30 is the second, and the PPF-2RAC30 is almost coincident with the. When the substitution rate is $50 \%$, the effect of the single doped fiber on the elastic modulus of concrete is relatively low, the substitution rate of RAC is smaller, the RAC of the two kinds of polypropylene fiber is almost the same, but the RSF-1RAC50 and RAC50 are almost coincident.

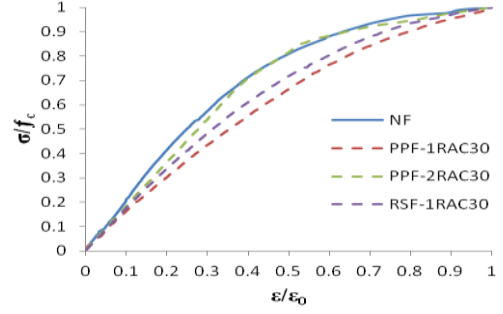

(a) $30 \%$

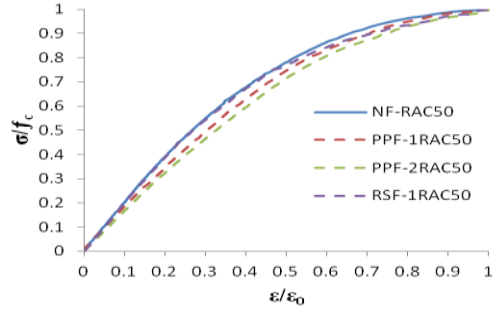

(b) $50 \%$

Figure 3. stress strain curve (rise) of single fiber RAC

\section{Conclusion}

Add (PPF-1, PPF-2, RSF-1) fiber, the flexural strength of RAC were higher than that of the reference concrete, and increased significantly, the largest increase of substitution rate was 50\% with RSF-1 regeneration of radial steel wire fiber, increased by $27.8 \%$, the smallest increase has reached about $11 \%$, visible in the concrete fiber has good toughening effect. For the peak strain, in a single fiber, the peak strain decreased with the added fiber; the elastic modulus in concrete NC doped fiber, reducing the elastic modulus of concrete, but the replacement rate is $30 \%$ and $50 \%$ of the RAC doped fiber, in addition to replace the rate of $30 \%$ and 50\% RAC addition RSF-1, elastic modulus were decreased by $5.8 \%$ and $2.5 \%$, the rest of the fiber elastic modulus of RAC were improved.The replacement rate is $30 \%$ and $50 \%$ PPF-1, and in PPF-2 doped and RSF-1 and fiber RAC, tangential slope is basically the same, but the stress continues to increase, not adding fiber RAC30 and RAC50, the tangent modulus of elasticity is relatively large, while adding fiber concrete tangential elastic modulus decreased. For the RAC with the substitution rate of $30 \%$, the strain of PPF-1 concrete under the same stress is greater than that of PPF-2 and RSF-1, and the shear modulus is the lowest. When the substitution rate is $50 \%$, the elastic modulus is relatively low and the substitution rate is less than RAC.

\section{References}

[1] Wu Bao, Xue Bin, Feng Xing. Study on the influence of polypropylene fiber reinforced recycled concrete on performance $[\mathrm{J}]$. Journal of Hebei Institute of Architecture and Civil Engineering, 2015, 35 (4): 16-19.

[2] Du Yuanfang, Wang Sheliang, Yu Binshan, et al. Mixed recycled fiber on strength of recycled concrete to study the effect of [J]. industrial construction, 2013, 43 (11): 12-15.

[3] Li Chuanchuan, Sun Liping,Zhu Haitang, et al. Study on the influence of steel fiber on the splitting strength of concrete [J] Journal of Hebei University of Technology, 2014, 43 (6): 47-49.

[4] Chen Aijiu, Chen Meng, Hu Fengqi, et al. Effect of basalt fiber on mechanical properties of recycled rubber concrete [J]. concrete, 2015, (2): 59-62.

[5] Niu Jiangang, Li Jingjun, Yin Yaliu, et al. Experimental study on mechanical properties and optimum fiber content of plastic fiber lightweight aggregate concrete [J]. silicate bulletin, 2016, 35 (1): 87-91. 
[6] Jiang Jian, Xu Hui. Experimental study on compressive behavior of recycled concrete under different modification [J]. concrete, 2014, (11): 87-89.

[7] Zhou Jinghai, Liu Zihe, Li Tingting, et al. Experimental study on splitting tensile strength of waste fiber recycled concrete [J]. Journal of Shenyang Construction University (NATURAL SCIENCE EDITION), 2013, 29 (5): 796-801.

[8] Xiao Jian Zhuang. Recycled concrete [M]. Beijing: China Building Industry Press, 2008.

[9] GB/T 50081-2002. Standard Test Method for mechanical properties of ordinary concrete [S]. Beijing: China Architecture and Building Press, 2003. 